Noonan, J. P. A. \& ANanth, J. (1977) Compulsive water drinking and water intoxication. Comprehensive Psychiatry, 18, 183-187.

\section{Phobia and childhood parental loss}

SIR: The recent report by Tweed et al (Journal, June $1989,154,823-828$ ) that agoraphobia with panic attacks and, to a lesser extent, simple phobia in an adult community sample are associated with parental loss or separation in childhood is an important contribution to our understanding of the aetiology of phobic disorders. However, certain limitations imposed by their method, particularly as they affect the interpretation of the negative results, should be noted.

Any interview procedure that screens for categorical cases will inevitably misclassify a proportion of borderline subjects. So long as there is no consistent bias in favour of over or under-diagnosis, this misclassification will not affect the estimation of prevalence rates for a disorder. However, the presence of false positives in the case group will confound the search for factors associated with the disorder in question, and studies of correlates based on unmodified survey data are likely to underestimate the significance of any associations. This problem can be overcome in two ways, either by excluding borderline subjects from studies of correlates (Robins, 1985), or else by verifying the subjects' case/non-case status according to particular rules in a follow-up casecontrol study. The advantage of the latter strategy is that it allows a more sensitive estimation of the significance of associations, particularly if there is pairwise matching of cases and controls.

The findings of Dr Tweed et al have been derived from a simple comparison of screen-positive and screen-negative survey subjects. This probably does not detract from the significance of the association reported between phobic disorders and childhood parental loss; indeed, a more rigorous approach might have demonstrated a stronger link. Where this study may have failed to do justice to the data is with regard to possible associations between childhood parental loss and other disorders such as social phobia and generalised anxiety disorder, and between anxiety disorders and specific maternal or paternal loss.

United Medical and Dental Schools

JAMES LINDESAY

Guy's Campus

London Bridge

London SE1 9RT

Reference

Rosns, L. N. (1985) Reflections on testing the validity of psychiatric interviews. Archives of General Psychiatry, 42, 918-924.

\section{Flaubert's complaint}

SIR: I was interested to read in a recently published biography of Gustave Flaubert (Lottman, 1989) that he suffered from epilepsy, probably of temporal lobe origin (Gastaut \& Gastaut, 1982). The biography also contains ample evidence of Flaubert's compulsive promiscuity and passion for writing, which be described as his "idée fixe". In a letter to one of his many female lovers he remarks, "I write a love letter to write, and not because I love". His great interest in religious matters is well known to any reader of his works, which include Herodias, La Tentation de Saint Antoine, and Legend de Saint Julian Hospitalor. Of himself he once said, "One must live as a bourgeois and think as a demi-god".

Several authors, including Trimble (1986), have drawn attention to a specific interictal syndrome associated with temporal lobe epilepsy and consisting of disorders of sexual function, hypergraphia, and hyperreligiosity. It seems probable that Flaubert suffered from this syndrome, but unlike many other fellow-sufferers, he was a genius able to turn his own pathology into art.

\section{Gordon Hospital}

Bloomburg Street

London SWIV $2 R H$

\section{References}

Gastaut, H. \& Gastaut, Y. (1982) La maladie de Gustave Flaubert. Revue Neurologique, 6-7, 467. Lotrman, H. (1989) Flaubert. London: Methuen.

TrimbLE, M. R. (1986) Hypergraphia. In Aspects of Epilepsy and Psychiatry (eds M. R. Trimble \& T. Bolwig), pp 75-87. Chichester: Wiley.

\section{The damnation of benzodiazepines}

SIR: The paper by Kraupl Taylor (Journal, May $1989,154,697-704)$ is timely. His use of the term 'anxiety illness' applies to most of the multitude suffering from various forms of disabling and often chronic anxiety. A look back to the condition of such patients before benzodiazepines became available about 30 years ago reminds us of the very unsatisfactory medication (e.g. barbiturates and amphetamines) commonly prescribed, not to mention the physical treatments and even psychosurgery resorted to in desperation by those seeking relief from intolerable anxiety. With the benzodiazepines, the improvement for many by way of the relief of symptoms was impressive. They were able to live "tolerable and reasonably normal lives, taking fairly full advantage of their abilities". Many were able to go out alone, 